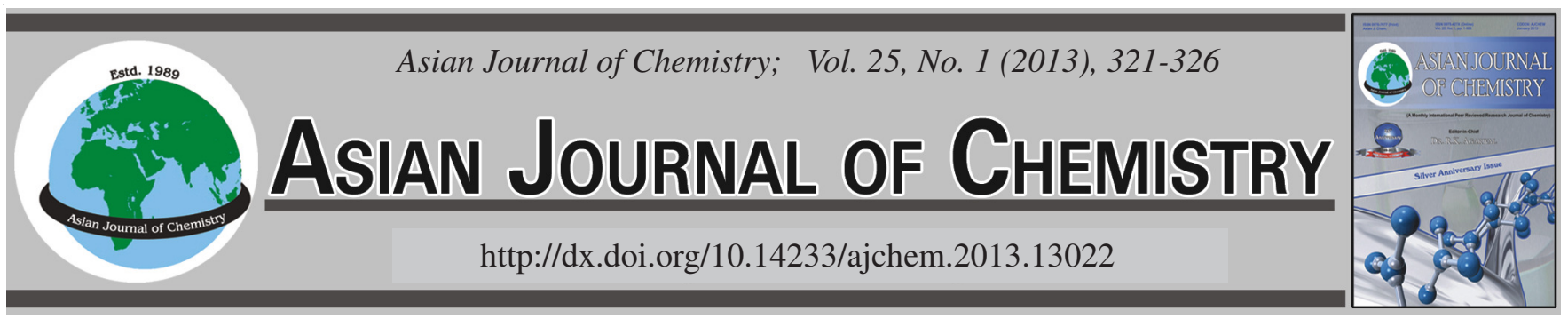

\title{
Separation of Methanol-Toluene Azeotropic Mixture by Extractive Distillation
}

\author{
Ke Tang ${ }^{1,2, *}$, Peng BaI ${ }^{1,2}$, Jinwei Zhang ${ }^{1,2}$ and Yi Huo ${ }^{1,2}$
}

${ }^{1}$ School of Chemical Engineering and Technology, Tianjin University, Tianjin 300072, P.R. China

${ }^{2}$ Key Laboratory of Systems Bioengineering, Ministry of Education, Tianjin University, Tianjin 300072, P.R. China

*Corresponding author: E-mail: tangke1984@126.com; 15002207786@126.com

Key Words: Methanol, Toluene, Extractive distillation.

\section{INTRODUCTION}

Binary mixtures, which form azeotropes or close-boiling mixtures, are common in the pharmaceutical and fine chemical industries and are characterized as behaving like a pure component when submitted to a distillation process. It is impossible to achieve the separation of azeotropic mixtures through conventional methods. Extractive distillation is a common process used to separate these kinds of mixtures with a third component, a salt solution or a solvent as the entrainer ${ }^{1}$. The function of the entrainer is to increase the relative volatility of the mixture. In this way, the components boil separately, which allows the collection of heavier components (solvent and heavy key) at the bottom of the distillation column and the light key component at the top ${ }^{2,3}$.

Methanol-toluene mixtures are commonly encountered in the fine chemical and pharmaceutical industries. The methanol-toluene mixture forms a minimum boiling point azeotrope at a mass composition of $68 \%$ methanol at a constant pressure of $101.3 \mathrm{kPa}^{4}$. Studies using pervapouration have been reported to determine the displacement of the methanoltoluene azeotrope ${ }^{5-8}$. However, all these processes were unable for industrial application due to the high operating costs, operative problems and their feasibility is still being studied in labs. On the contrary, the technology of extractive distillation is suitable for industrial application.
The aim of this work is to study the vapour-liquid equilibrium (VLE) of methanol-toluene- $o$-xylene system and furthermore to establish industrial operating conditions for the extractive distillation process of methanol-toluene by using $o$-xylene as the entrainer.

\section{EXPERIMENTAL}

The component mass fraction of raw material is 0.68 methanol and 0.32 toluene. The purity of $o$-xylene is 0.995 (mass fraction).

Batch distillation experiments were carried out in a small laboratory column to evaluate the performance of the solvent. The column has a total height of $1.5 \mathrm{~m}$ and an internal diameter of $25 \mathrm{~mm}$. It is packed with stainless steel $\theta$-rings of $\Phi 3 \mathrm{~mm} \times 3 \mathrm{~mm}$. The total packing height is about 40 theoretical plates and the total liquid hold up is $40 \mathrm{~mL}$. The bottom is a flask of $2000 \mathrm{~mL}$ with three openings. The solvent is fed to the column near the top section. The flow rate is controlled by a flowmeter. The reflux ratio is provided at the top of the column by a solenoid valve. The sketch map is showed in Fig. 1.

The methanol, toluene, $o$-xylene and other high boiling organic impurity composition are determined by a GC-SP6890 gas chromatograph with a TCD detector and with a GDX102 column. The injector and detector temperature are held $150{ }^{\circ} \mathrm{C}$ while the column temperature is set equal to $100^{\circ} \mathrm{C}$. 


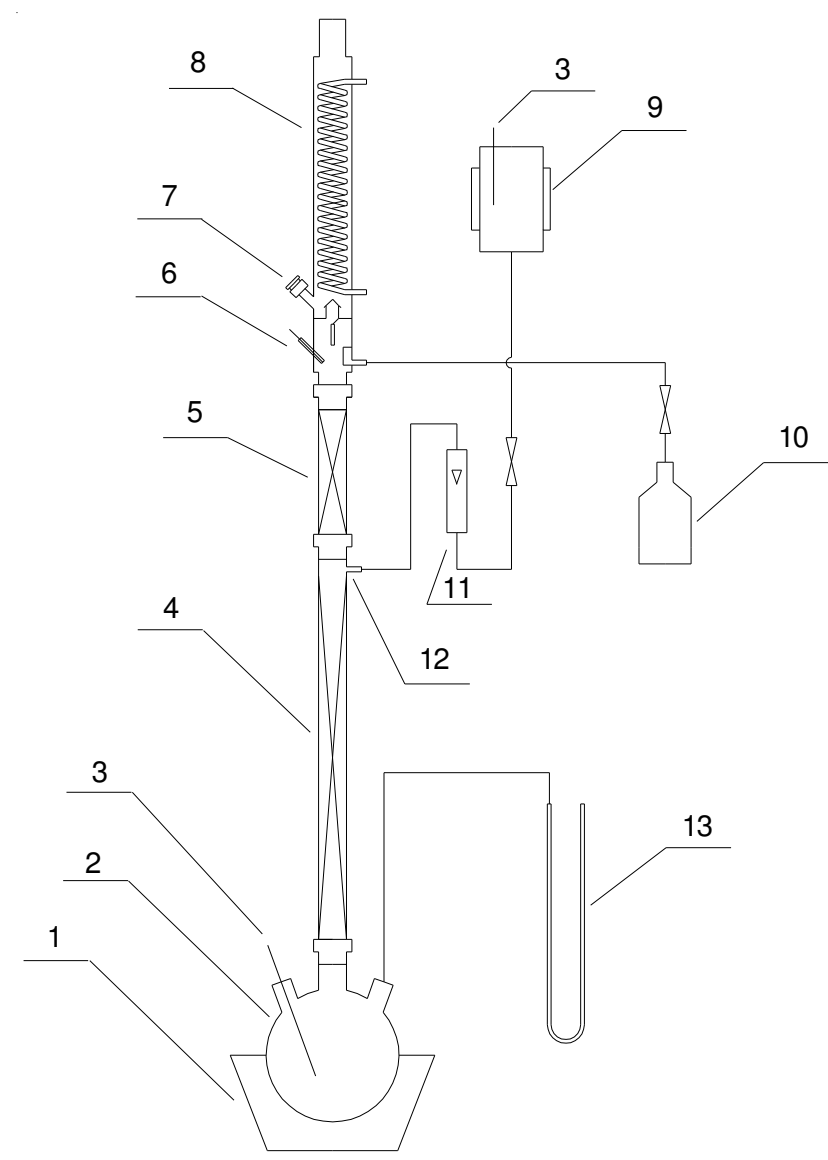

$1=$ Heating jacket; $2=$ Flask; 3,6 = Thermometer; $4=$ Extractive rectifying section with insulation; $5=$ Rectifying section with insulation; $7=$ Sample connection; 8 = Condenser; $9=$ Storage tank of solvent; $10=$ Distillate receiver; $11=$ Flowmeter; $12=$ Solvent inlet; $13=$ U-type pressure meter

Fig. 1. The experiment equipment

Experiment procedure: $615 \mathrm{~mL}$ original methanoltoluene mixture was charged into the bottom. Then it was heated and kept under total reflux for $0.5 \mathrm{~h}$. The condenser was subcooled to and the power for boiler heating is $400 \mathrm{~W}$. When the temperature of the bottom and the condenser was steady, $o$-xylene was charged into the column near the top section of the column at a speed of $10 \mathrm{~mL} / \mathrm{min}$, then kept total reflux $0.5 \mathrm{~h}$ again. The purpose of this step was to decrease the concentration of toluene at the top product. After the total reflux, the distillate was withdrawn at a reflux ratio of 3 . The analysis of the distillate composition was performed about every $5 \mathrm{~min}$. The temperatures of the top and the bottom of the column were recorded every $5 \mathrm{~min}$. When the top temperature exceeded $110^{\circ} \mathrm{C}$, it showed that the methanol in the raw material had been withdrawn completely. At this moment, the solvent should be stopped to charge. The top product will be toluene in turn. When toluene at the top product achieved below $95 \%$, this solvent at the bottom was collected for recycle.

\section{RESULTS AND DISCUSSION}

The experimental results are shown in Figs. 2 and 3. Time 0 started from the qualified distillate withdrawn step. It can be seen that, at the beginning, the concentration of methanol in distillate maintained a high value that is over $99 \%$ wt averaged and the yield is about $79 \%$. When it processed for $70 \mathrm{~min}$, the

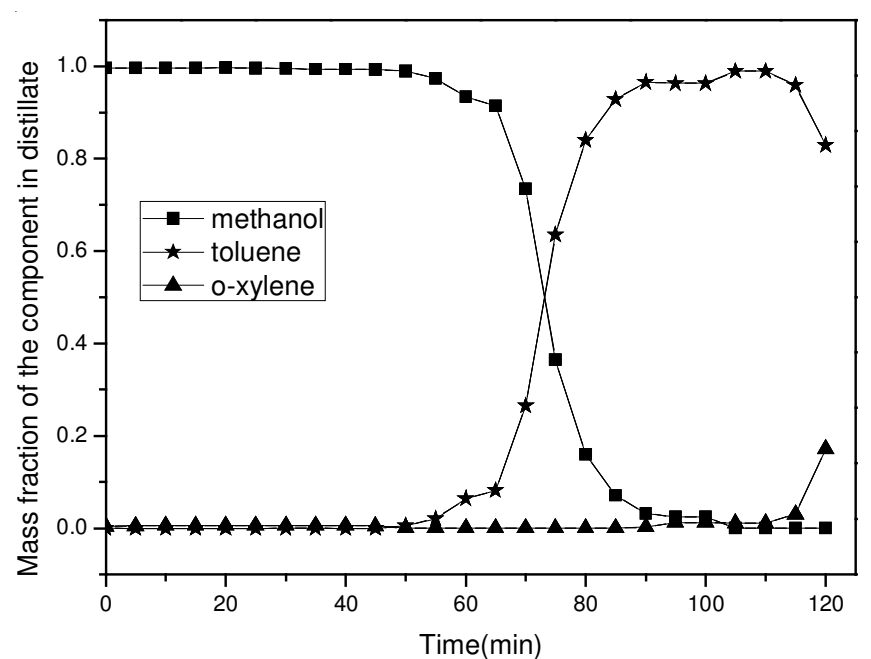

Fig. 2. Variation of the distillate composition in the experiment

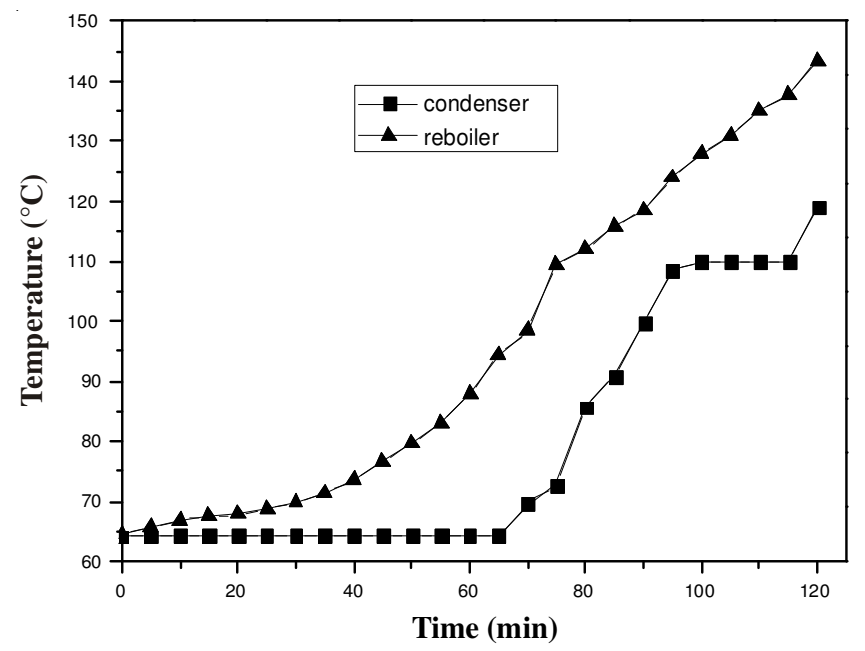

Fig. 3. Temperature of reboiler and condenser in the experiment

methanol mass fraction at the top decreased while the concentration of toluene increased gradually. But the solvent in the distillate was close to zero all the time. This distillation cut was transition distillate. As there was lots of methanol in this part of distillate, it could not be thrown away but recycled with the mixture in the next process. After 90 min, the concentration of methanol in the distillate decreased sharply while the toluene mass fraction increased until reached over $95 \%$. This step continued for about $25 \mathrm{~min}$. At this moment toluene had been almost removed from the system. The results showed that the withdrawal of transition distillate cut maintained about $15 \mathrm{~min}$. The methanol concentration in transition distillate cut is high which lead to decreased yield.

In the experiment, the temperature of the top is stable at the qualified methanol withdrawn step. The top temperature is nearly the b.p. of pure methanol. When toluene is withdrawn the top vapour-phase temperature is around $112^{\circ} \mathrm{C}$, which is a little higher than the b.p. temperature of toluene. The main reason is that there is little solvent remained at the top product. While the solvent is charged into the column, toluene is carried to the bottom by $o$-xylene. There is more and more solvent at the bottom, so the bottom temperature increases all the time. 
Vapour-liquid equilibrium (VLE) of methanol-toluene$\boldsymbol{o}$-xylene system: The ternary vapour-liquid equilibrium (VLE) of methanol-toluene- $O$-xylene system was determined experimentally. Briefly, mixtures of methanol-toluene with $o$-xylene at $101.3 \mathrm{kPa}$, were prepared in a vapour-liquid equilibrium still. After the vapour-liquid equilibrium was achieved (constant temperature throughout the system), samples of condensed vapour and liquid were taken for GC analysis. Each assay was made in duplicate. Fig. 4 shows the pseudo-binary diagram obtained for a solvent to feed molar ratio $(\mathrm{E} / \mathrm{F})$ of 1 . Three thermodynamic models (Wilson, NRTL and UNIQUAC) were analyzed to determine which model was most suitable to predict the system performance. The obtained results show that the NRTL model presented the highest accuracy.

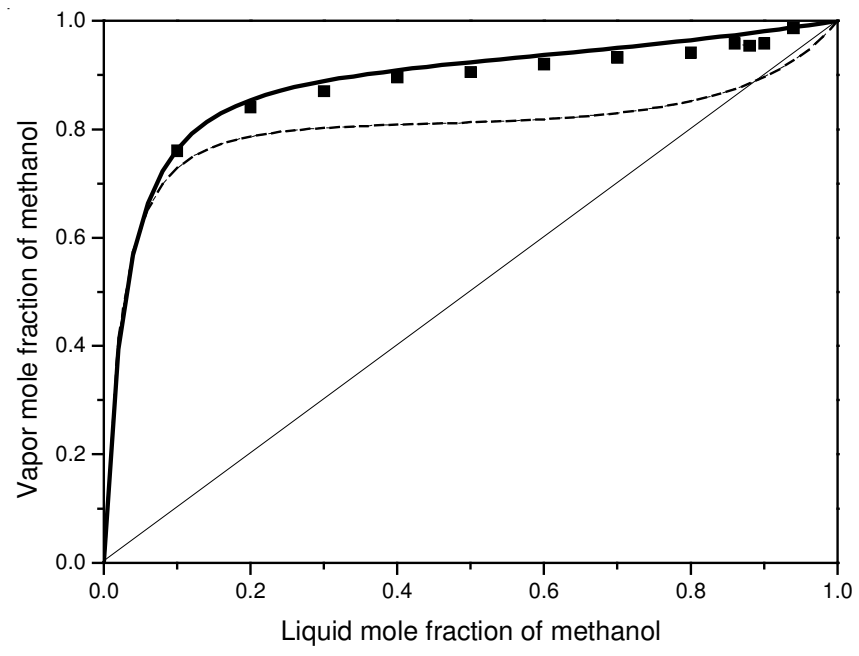

Fig. 4. Pseudo-binary equilibrium curve for methanol-toluene with $o$-xylene at $101.3 \mathrm{k} \mathrm{Pa}$. Solid and dashed lines predicted by NRTL model for the pseudo-binary and binary systems, respectively

Simulation of the process: The separation of methanoltoluene mixture was carried out by using $o$-xylene as the entrainer. The simulation of the process was performed with the chemical process simulation software-Aspen Plus V7.0. The NRTL model was used to predict the activity coefficients and ideal gas model to predict the fugacity coefficient. The binary interaction parameters of methanol-toluene were from "APV70VLE-IG" databank in Aspen, while the ones of methanol-o-xylene and toluene-o-xylene were estimated by using Standard UNIFAC vapour-liquid equilibrium formulation.

Fig. 5 presents the residue curve map for the methanoltoluene- $o$-xylene system. The azeotropic mixture of methanol (b.p. $64.53^{\circ} \mathrm{C}$ ) and toluene (b.p. $110.68^{\circ} \mathrm{C}$ ) presents a minimum boiling point at $63.87^{\circ} \mathrm{C}$ at $101.3 \mathrm{kPa}$. It was observed that $o$-xylene was a feasible entrainer for the methanol-toluene separation because the residue curve map had the optimal configuration for the extractive distillation.

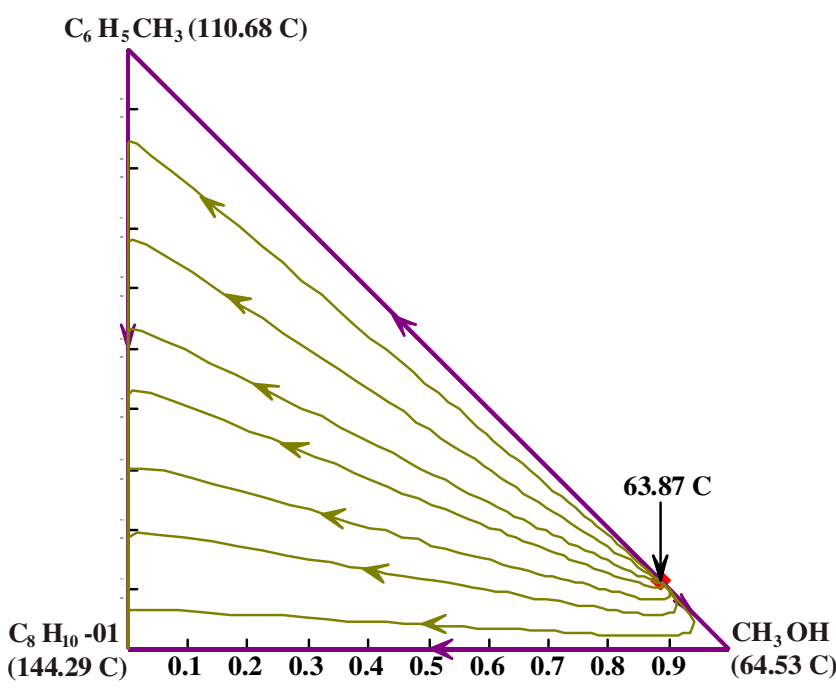

Fig. 5. Residue curve map for methanol-toluene-o-xylene system at 101.3 $\mathrm{kPa}$ calculated by using the NRTL model

The flowsheet of the extractive distillation process is presented in Fig. 6. The process has two columns, one for extractive distillation and the other for solvent recuperation. The azeotropic mixture and the solvent are fed to the first column, in which the components boil separately which allows the less volatile components to collect at the bottom and the light key component at the top. The bottom product is fed to the second column, in which the solvent is recovered and recycled to the extractive distillation column.

Sensitivity analysis: To establish the operating conditions for the extractive distillation process, a sensitivity analysis was done.

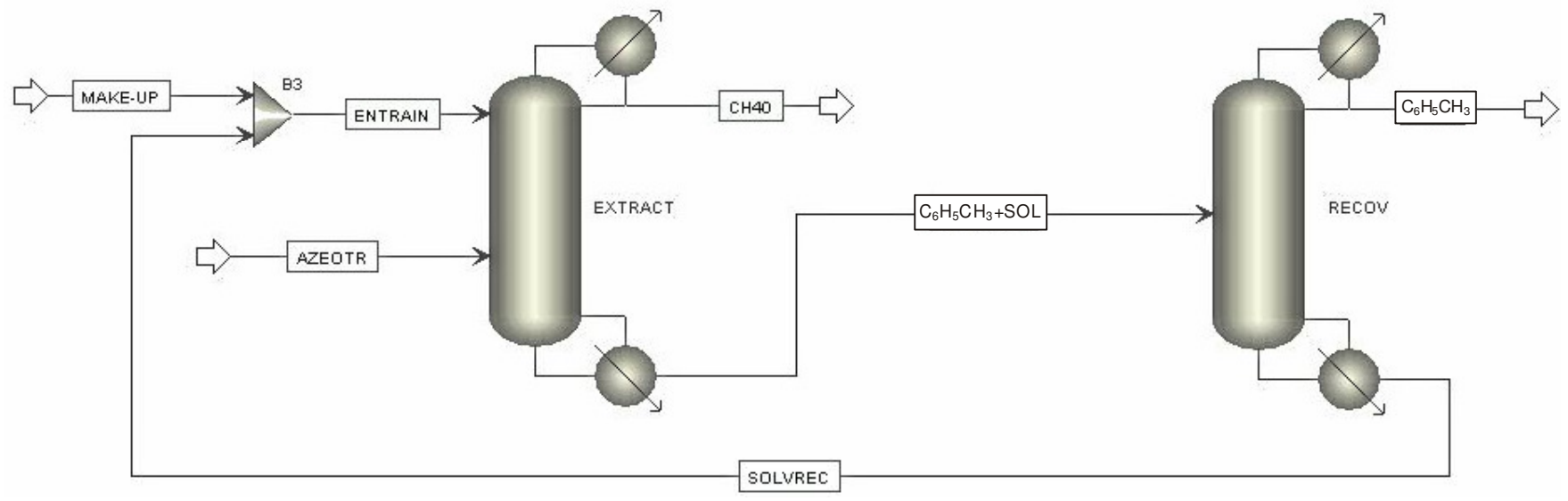

Fig. 6. Extractive distillation flowsheet 
Effect of azeotropic mixture feed stage: In Fig. 7, the effect of azeotrope feed stage on the molar composition of distillate in the extractive column and reboiler energy consumption is presented. It can be observed that, as the azeotropic feed stage was closer to the reboiler, the mole fraction of methanol in distillate increased; so did the reboiler energy consumption. The purity and energy consumption reached a maximum when feed stage is 27 . This meant that the biggest separation took place in the rectifying section. In order to obtain the methanol composition required in the distillate and decrease the reboiler energy consumption, the stage near the reboiler should be chosen as the suitable azeotrope feed stage.

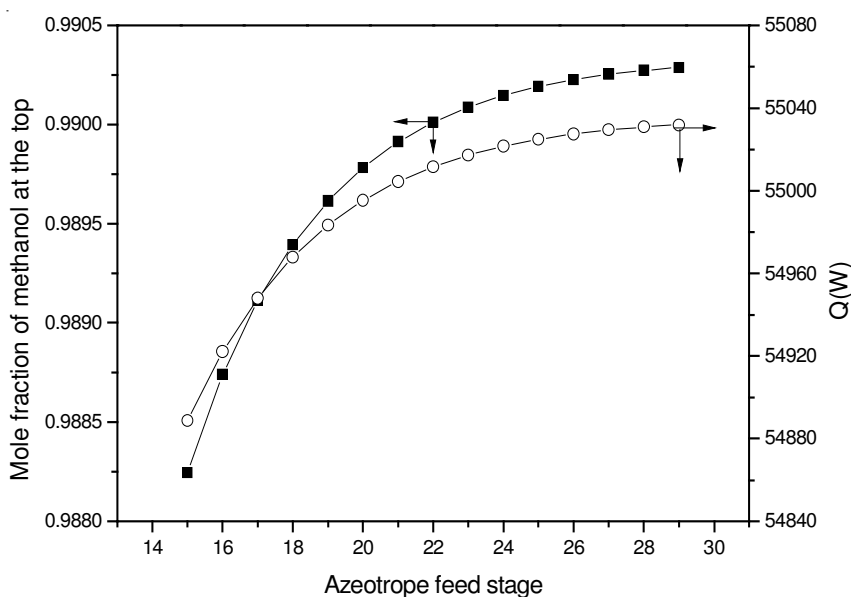

Fig. 7. Effect of azeotrope feed stage in the extractive distillation column with $o$-xylene on distillate composition and reboiler energy consumption

Effect of reflux ratio: Fig. 8 shows that the change of molar reflux ratio has a great effect on the distillate composition and reboiler energy consumption. The results showed that the purity reached a maximum as molar reflux ratio increased, because as the reflux rate increased, the solvent was diluted in the column. The results also showed that the reboiler energy consumption increased sharply with the increase of molar reflux ratio. The liquid brought by reflux must be vapourized, so the molar reflux ratio should be as low as possible to decrease the reboiler energy consumption.

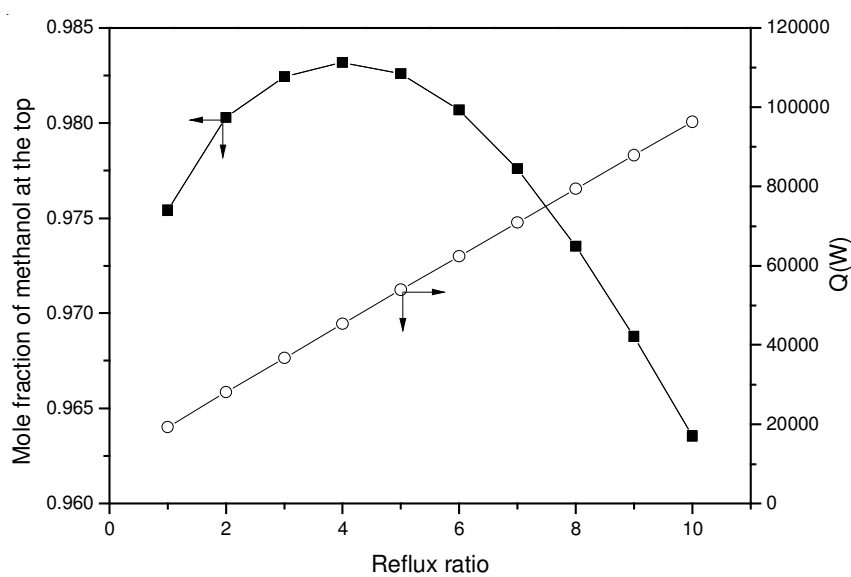

Fig. 8. Effect of molar reflux ratio in the extractive distillation column with $o$-xylene on distillate composition and reboiler energy consumption
Effect of solvent to feed ratio (S/F): Solvent to feed ratio (S/F) has a direct effect on the distillate purity. In Fig. 9, as $\mathrm{S} / \mathrm{F}$ molar ratio approached to 0.5 methanol content increased, after which it was stable. This occurred because more solvent may enlarge the relative volatility of the methanoltoluene mixture. However, the purity of methanol was so high that it is not necessary to increase S/F sequentially. Rising of $\mathrm{S} / \mathrm{F}$ increased the liquid flow in the reboiler. Although the liquid brought by the solvent remained in liquid phase in column, it may absorb heat in the column. Taking into consideration the situation that high $\mathrm{S} / \mathrm{F}$ ratios increased the energy consumption in reboiler, $\mathrm{S} / \mathrm{F}$ should not be too large.

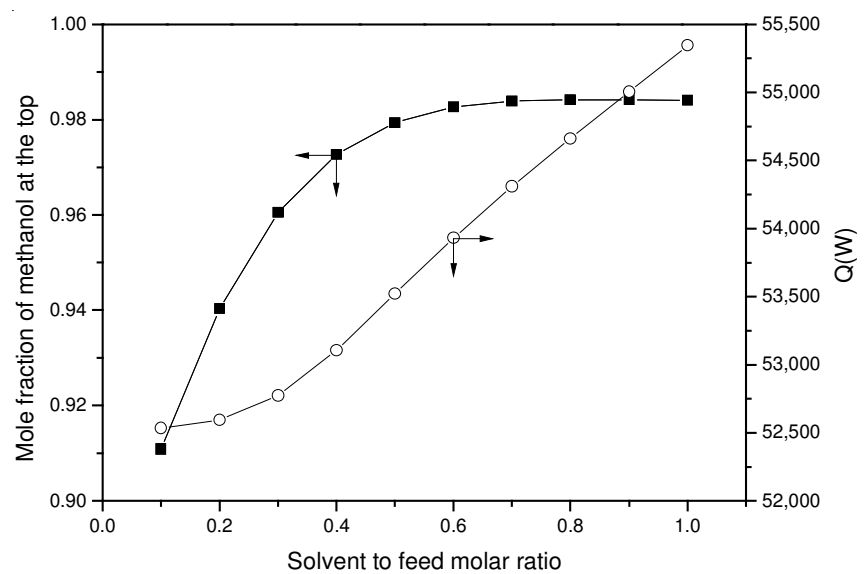

Fig. 9. Effect of S/F molar ratio in the extractive distillation column with $o$-xylene on distillate composition and reboiler energy consumption

Effect of entrainer feed stage: Fig. 10 shows that is not greatly affected by changes on the 8-14 stage in the distillate mole fraction when the solvent is fed. As the solvent feed stage approached to the condenser methanol content increased up to a maximum, after which it decreased. This decrease was because that the vapourization of the $o$-xylene entered into the column, which became part of the vapour that flowed up to the condenser and that was withdrawn as distillate.

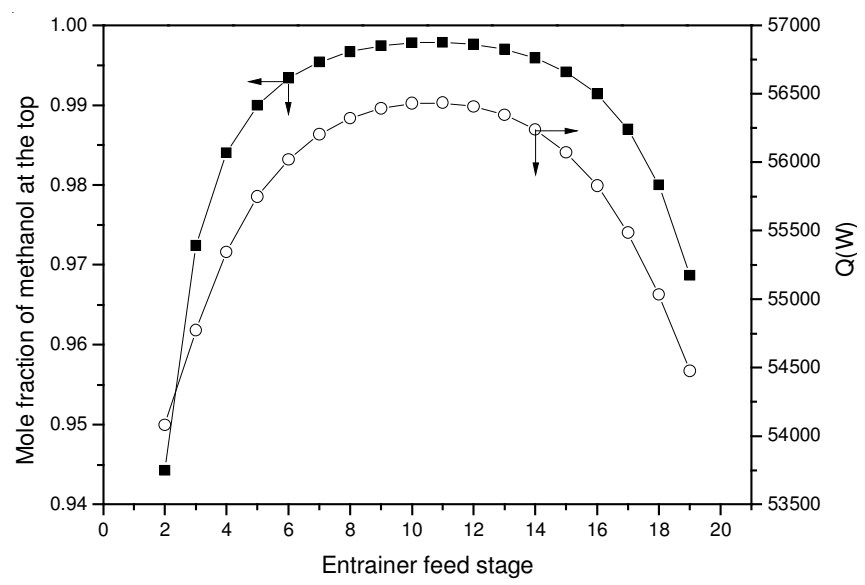

Fig. 10. Effect of solvent feed stage of the distillation column with $o$-xylene on distillate composition and reboiler energy consumption

Based on the sensitivity analysis above, the best configuration and operating conditions of the columns was found and presented in Table-1. 
TABLE-1

OPTIMAL DATA FOR THE DISTILLATION COLUMNS

\begin{tabular}{lcc}
\hline \multicolumn{1}{c}{ Parameter } & $\begin{array}{c}\text { Extractive } \\
\text { column }\end{array}$ & $\begin{array}{c}\text { Recovery } \\
\text { column }\end{array}$ \\
\hline Azeotropic feed flowrate $(\mathrm{kmol} / \mathrm{h})$ & 1 & - \\
Number of stages & 30 & 30 \\
Solvent feed stage & 12 & - \\
Azeotrope feed stage & 23 & 14 \\
Solvent feed temperature $\left({ }^{\circ} \mathrm{C}\right)$ & 80 & - \\
Azeotrope feed temperature $\left({ }^{\circ} \mathrm{C}\right)$ & 30 & - \\
Mole fraction of methanol in azeotropic feed & 0.885 & - \\
Solvent feed flow rate $(\mathrm{kmol} / \mathrm{h})$ & 0.7 & - \\
Mole fraction of $o$-xylene in solvent feed & 1 & - \\
Reflux ratio & 3 & 9 \\
\hline
\end{tabular}

Simulation results: The simulation results were presented in Table-2. It was shown that the obtained methanol mole composition at the extractive column top was 0.999 and the toluene mole composition at the recovery column top was 0.997 . Meanwhile, the $o$-xylene which was 0.999 in mole composition was obtained at the bottom of the recovery column.

\begin{tabular}{lccc}
\multicolumn{4}{c}{ TABLE-2 } \\
\multicolumn{4}{c}{ SIMULATION RESULTS FOR THE PROCESS FLOWSHEET } \\
\hline & $\mathrm{CH}_{3} \mathrm{OH}$ & $\mathrm{C}_{6} \mathrm{H}_{5} \mathrm{CH}_{3}$ & SOLVREC \\
\hline Temp. $\left({ }^{\circ} \mathrm{C}\right)$ & 64.5 & 108.0 & 143.7 \\
Mole flow $(\mathrm{kmol} / \mathrm{h})$ & 0.886 & 0.114 & 0.7 \\
Mole fraction & & & \\
Methanol & 0.999 & 0.002 & trace \\
Toluene & $548 \mathrm{ppm}$ & 0.997 & 0.001 \\
$o$-Xylene & $859 \mathrm{ppm}$ & $953 \mathrm{ppm}$ & 0.999 \\
\hline
\end{tabular}

In Fig. 11, the temperature profile in the extractive distillation column showed a temperature change at stage 12 due to the entrainer inlet, whereas at stage 23 the temperature had a minimal decrease because of the azeotropic mixture feeding. A significant temperature increase was observed at stages 29 and 30 due to the reboiler proximity.

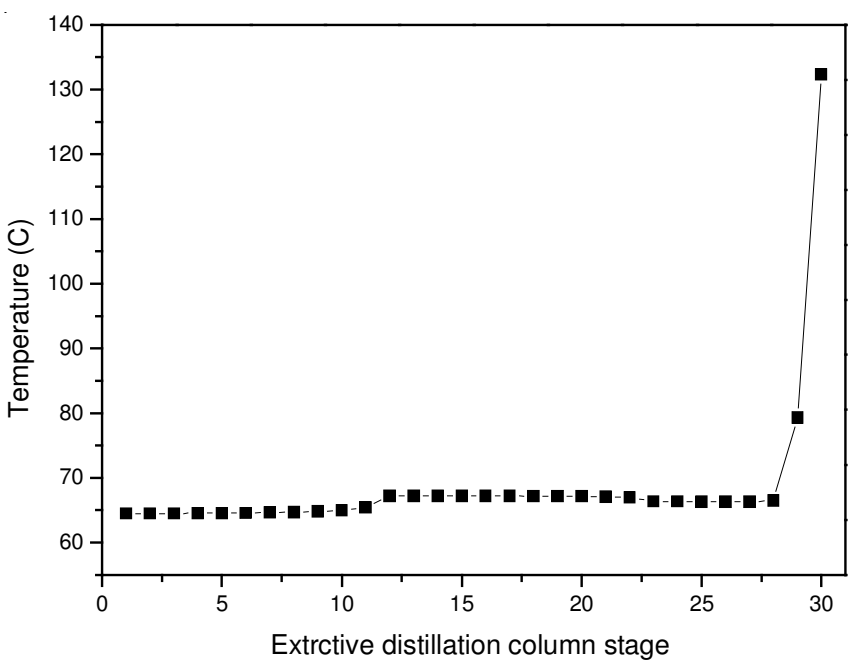

Fig. 11. Extractive distillation column temperature profile

Fig. 12 presents the liquid and vapour molar flow rate profiles in the extractive column. The liquid molar flow exposed two significant changes due to the solvent and the azeotropic mixture feed at stages 12 and 23, respectively. Meanwhile, the vapour molar flow rate remained constant along the column, except at stage 12 in which the solvent was fed. This change was caused by the liquid-phase vapourization due to the $o$-xylene inlet temperature.

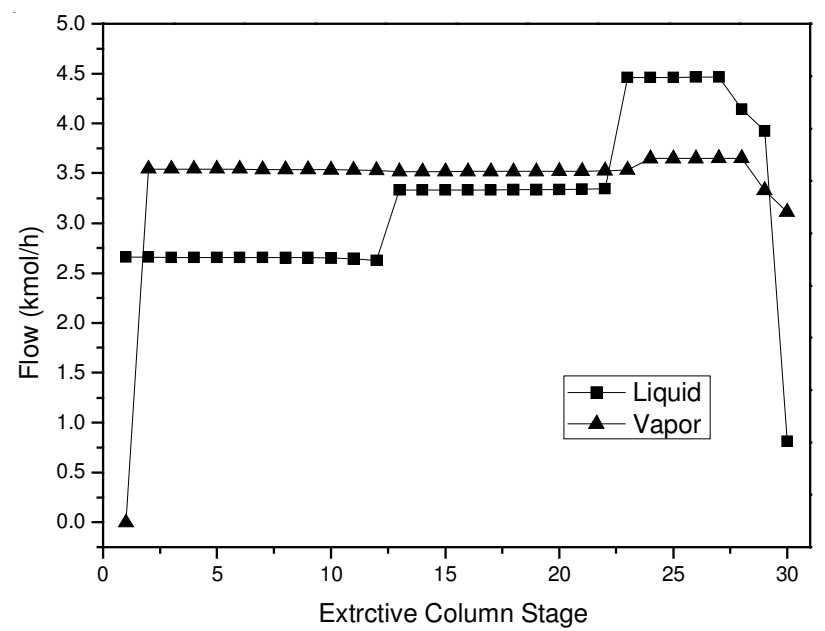

Fig. 12. Liquid and vapour molar flow rate profiles in the extractive distillation column

Fig. 13 showed that the methanol concentration decreased at stage 12 in which the entrainer was fed. Toluene composition became appreciable at stage 13 and from this stage until the bottom of the column the composition was increased. At stage 23 , the observed change on toluene composition was due to the azeotropic mixture feed. The $o$-xylene profile had a significant change at stage 12 in which it is fed. The main product at the top of the column was methanol and at the bottom the main components were toluene and $o$-xylene. Meanwhile, in Fig. 14, for the liquid molar composition profiles, methanol and $o$-xylene had an important change at stage 12 , in which the methanol composition decreased significantly and $o$ xylene increased due to the entrainer inlet. The feed of azeotropic mixture at stage 23 caused an increase in methanol composition, whereas a decrease in $o$-xylene composition was observed. The methanol composition decreased along the column and at the bottom only $o$-xylene and toluene were present. Toluene exposed only one significant change at stage 23 in which the binary mixture was fed.

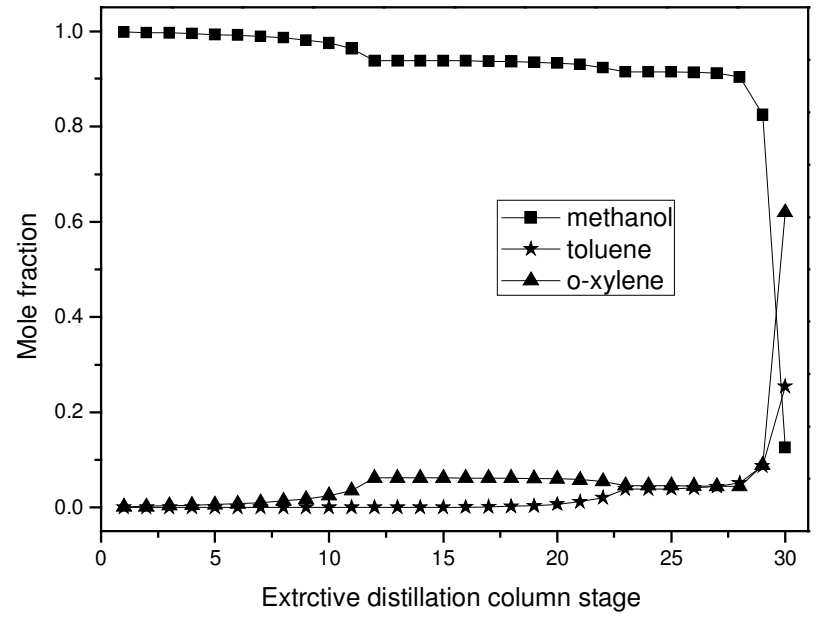

Fig. 13. Vapour-phase concentration profiles of methanol, toluene and $o$-xylene in the extractive distillation column 


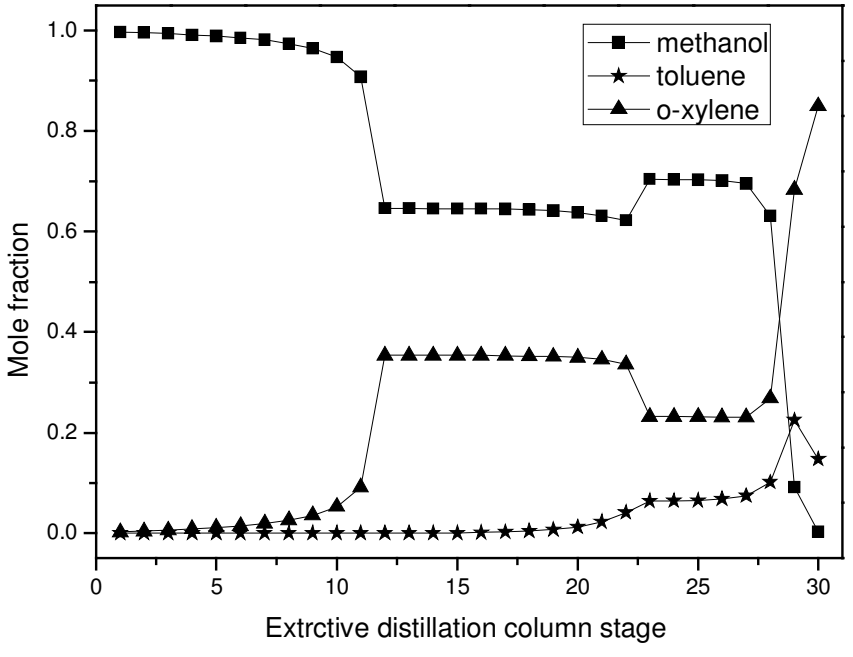

Fig. 14. Liquid-phase concentration profiles of methanol, toluene and $o$-xylene in the extractive distillation column

\section{Conclusion}

$o$-Xylene was chosen as the entrainer to achieve the separation of the azeotropic mixture methanol-toluene by extractive distillation. NRTL model was the most suitable one to predict vapour-liquid equilibrium (VLE) of methanoltoluene-o-xylene system. The feasibility of the process was confirmed via simulation and experiments. Sensitivity analysis was done to obtain the best conditions and configuration for extractive and recovery columns. The temperature, composition and molar flow profiles obtained for the extractive distillation column were consistent. In both the simulation and experiments, high purified methanol and toluene were obtained respectively.

\section{REFERENCES}

1. B. Kotai, P. Lang and G. Modla, Chem. Eng. Sci., 62, 6816 (2007).

2. E. Batista and A. Meirelles, J. Chem. Eng. Jpn., 3, 45 (1997).

3. P. Langston, N. Hilal, S. Shingfield and S. Webb, Chem. Eng. Process., 44, 345 (2005).

4. D.E. Burke, G.C. Williams and C.A. Plank, J. Chem. Eng. Data, 9, 212 (1964).

5. S.M. Pal and V. G. Pangarkar, J. Appl. Polym. Sci., 96, 243 (2005).

6. S.J. Lue, J.S. Ou, C.H. Kuo, S.Y. Chen and T.H. Yang, J. Membr. Sci., 347, 108 (2010).

7. P. Garg, R.P. Singh and V. Choudhary, Sep. Purif. Technol., 76, 407 (2011).

8. S. Mandal and V.G Pangarkar, J. Membr. Sci., 201, 175 (2002). 